\title{
ON THE EFFECTS OF LOCAL VERSUS CENTRAL GOVERNMENT FINANCING OF LOCAL SERVICES
}

\author{
Muhammed N. Islam*
}

\begin{abstract}
This paper provides some empirical support for pricing a part of local services on user basis. A model of fiscal responses to grants/user fees, based on a vote-maximizing approach, is tested on both time series and pooled data (1977-1991) for 39 upper-tier municipalities in Ontario, Canada. The exogeneity specification of grants is tested and the test results are taken into account in estimating the model. The results indicate that roughly 70 percent of the municipal governments would find it cheaper to finance local spending by grants than by local taxation. If the grant system is abolished, a majority of these governments would prefer to use some sort of user fees in financing local services. The study suggests that local public services can be provided at a substantially lower per-unit cost if some selected services are priced on user basis.
\end{abstract}

\section{INTRODUCTION}

This paper examines whether local taxes or provincial grants (and user fees) are the more cost-effective means of financing local public services. A grant induces a belief among local residents that non-residents will share the cost of providing additional public services. This belief is based upon an assumption that marginal local expenditures are being financed by grants, which are to be funded mostly from taxes on other localities ${ }^{1}$. In other words, grants are viewed as a means of 'exporting' the tax burden to residents of other localities (Wildasin 1987).

If local politicians also perceive that each dollar of local grants is financed by a central (e.g., provincial) tax, then local spending will depend upon the net effect of each dollar of grant money received less the effect of financing grants to all communities. The net expenditure effect of each own grant dollar will be positive when the voter has to pay more per dollar of local services through local taxation than he would pay for the same service through provincial taxation. Given the choice between local and provincial taxation, all else equal, a rational voter would then prefer provincial financing of local services. There is an extensive literature on the expenditure effect of grants (see Courant et al. 1979, Gramlich 1977, Oates 1979, Romer et al. 1982, and Slack 1980). But no study has distinguished between local and central tax prices and analyzed their effects on local spending.

\footnotetext{
*Associate Professor of Economics, Concordia University, Montreal, Canada. The author is grateful to three anonymous referees for many helpful comments and suggestions.
} 
The purpose of this paper therefore is to make a distinction between local and central tax prices and analyze their effects on the spending decisions of individual municipalities in Ontario over the period 1977-1991. Section 2 presents a local expenditure model, derived by using the expected vote maximization (EVM) approach. ${ }^{2}$ Empirical estimates and other issues are discussed in the subsequent sections.

\section{THEORETICAL MODEL}

Assume the objective of a local government is to maximize its electoral support (votes), subject to its own budget constraint. The (expected) support is assumed to depend upon the level of satisfaction of the voters (residents), which are derived from the consumption of a bundle of public as well as private goods and services. The satisfaction of nonresidents involved in local economic activities is not formally introduced in the local government's objective function, as nonresidents are not entitled to vote in the local election.

The satisfaction of the ith voter can be expressed as a function of his perceived local services, measured by his total share of local expenditures $\left(\theta_{0 \mathrm{i}} \mathrm{E}\right)$, and his net income $\left(y_{d i}\right)$ spent on all private goods and services. Thus the utility function of the ith voter is written as

$$
\mathrm{U}_{\mathrm{i}}\left(\theta_{0 \mathrm{i}} \mathrm{E}, \mathrm{y}_{\mathrm{di}}\right) \text {, }
$$

where $\theta_{0 \mathrm{i}}$ is the voter's per-dollar share of local expenditures $(\mathrm{E})$.

The expenditure on private goods is represented by his after-tax income $\left(Y_{\mathfrak{i}}\right)$ less his income loss due to local taxation and grant financing. The income loss due to local taxation is measured by $\theta_{1 i} T$, where $T$ is the total revenues from municipal taxation and $\theta_{1 \mathrm{i}}$ is his per-dollar share of T. An estimate of $\theta_{1 \mathrm{i}}$ would provide a measure of the voter's local tax burden. Let his per-dollar share of taxes raised by the province to finance the system of grants to all municipalities $\left(G_{T}\right)$ be represented by a parameter $\theta_{2 \mathrm{i}}$. Then his share of costs in grant financing is equal to $\theta_{2 \mathrm{i}} \mathrm{G}_{\mathrm{T}}$. His share of the local user fees including miscellaneous charges ${ }^{3}\left(\mathbf{R}_{0}\right)$ can similarly be defined by $\theta_{3 i} R_{0}$. The parameters are not constrained to be equal. Assuming his after-tax income $\left(Y_{i}\right)$ already known to him, $y_{d i}$ can be written as

$$
y_{d i}=Y_{i}-\theta_{1 i} T-\theta_{2 i} G_{T}-\theta_{3 i} R_{0} .
$$


Both the expenditure and revenue aspects of a local government involve necessary costs. To simplify the derivation of the model, it is assumed that the local authority provides local services at a constant average cost of $\$ 1.00$. The own-source revenues are measured in net terms, that is, gross revenues minus various expenses incurred in raising them. Modelling, with the costs of raising revenues, is a difficult task (see Hettich and Winer 1984).

The electoral support for the government would be highest when eq.(1) is maximized for all voters subject to the government's own budget constraints. According to the Municipal Act, the government is obliged to balance its budget on the current account ${ }^{4}$ as well as to follow the relevant institutional arrangements with the province. Thus the budget constraint of the government can be written as

$$
E=T+R_{0}+G ; G=G_{T}-G_{0} \text {, }
$$

where $\mathrm{G}=$ the grants (conditional plus unconditional transfers) ${ }^{5}$ received by the municipality, and $G_{0}=$ the combined grants to all other municipalities in the province.

In the constrained-utility maximization the local government considers $\mathrm{E}$ and $\mathrm{T}$ as target variables. The choice of the municipal tax rate is a policy instrument at the discretion of the local government, so that $T$ (=the tax rate $x$ assessment base ${ }^{6}$ on which taxes are levied) can be assumed as endogenous; assessment base is exogenously determined by the provincial authority. It is initially assumed that grants are exogenously determined in local budget decisions. The user and other fees $\left(R_{0}\right)$ are also assumed as exogenous. The agent's after-tax income $Y$ can also be assumed as predetermined.

If the utility function is of the Stone-Geary type (see McGuire 1978), the constrained-maximization problem can then be captured by eq.(4)

$$
\operatorname{Max} L=\beta_{1} \ln \left(\theta_{0 i} E-\gamma_{1 i}\right)+\beta_{2} \ln \left(y_{d i}-\gamma_{2 i}\right)+\varphi\left(T+R_{0}+G-E\right),
$$

where $\beta_{1}+\beta_{2}=1, \beta_{1}, \beta_{2}>0 ; y_{d i}$ is given by eq.(2) and $\phi$ is a Lagrange multiplier incorporating the budget constraint in the objective function.

Eq.(4) describes the ith voter as buying the quantities of local public goods and all other goods in the amounts $\left(\gamma_{1 \mathrm{i}}, \gamma_{2 \mathrm{i}}\right)$ at the subsistence level and then dividing the remaining expenditures among these goods in fixed proportions $\left(\beta_{1}\right.$, $\beta_{2}$ ). The amounts of the subsistence levels of these goods are assumed to depend upon his (socio-economic) individual characteristics (e.g., his personal income, holdings of immovable assets proxied by the assessed valuation of his properties, household size, and age composition of his household members). Thus the nor- 
malizing variables $\gamma_{j}^{j}$ can be represented by

$$
\gamma_{j}^{i}=a_{. j 0}^{i}+\Sigma a_{j K}^{i} X_{k}^{i} ; \quad j=1,2 \text { and for all } i,
$$

where $\mathbf{X}_{\mathbf{k}}^{\mathrm{i}}$ represents the $k$ th characteristic of the ith voter.

The constrained-maximization of eq.(4) with respect to the target variables $E$ and $\mathrm{T}$ leads to a series of first-order conditions for equilibrium. Solving these conditions and using eq.(5) yield the following expenditure equation

$$
E=\alpha_{0}+\alpha_{1} Y+\alpha_{1}\left(\theta_{1}-\theta_{2}\right) G-\alpha_{1} \theta_{2} G_{0}+\alpha_{1}\left(\theta_{1}-\theta_{3}\right) R_{0}+\Sigma \alpha_{1 k} X_{k},
$$

where $\alpha_{0}=\left(\beta_{2} a_{10}-\alpha_{1} a_{20}\right), \alpha_{1}=\left(\beta_{1} / \theta_{1}\right)>0$, and $\alpha_{1 k}=\beta_{2} \alpha_{1 k}-\alpha_{1} a_{2 k}$ and the subscript $i$ is eliminated by averaging over all voters.

A positive coefficient on $G$ indicates that the centrally financed grants for local services will involve a net transfer of resources, which will stimulate local economic activities. The net transfer is equal to what is saved on local taxation per dollar of aid received $\left(\theta_{1} G\right)$, less what is paid to the provincial government per dollar of aid received $\left(\theta_{2} G\right)$. While $\left(\theta_{1} G\right)$ will increase local economic activities, $\left(\theta_{2} \mathrm{G}\right)$ will lead to a reduction in them. If we assume a common income response to $\theta_{1} \mathrm{G}$ and $\theta_{2} \mathrm{G}$, the change in local expenditures would be $\alpha_{1}\left(\theta_{1}-\theta_{2}\right)$ per dollar of aid received. Similarly, a common income response to $\theta_{1} R_{0}$ and $\theta_{3} R_{0}$ will lead to an expenditure change of $\alpha_{1}\left(\theta_{1}-\theta_{3}\right)$ per dollar of other revenues generated. The change in local expenditures will of course occur through changes in the perceived tax prices ${ }^{7}$ of the subsidized local public good.

A positive sign of the grant coefficient $\alpha_{1}\left(\theta_{1}-\theta_{2}\right)$ would imply that the local government would find it cheaper to finance local services by provincial grants than by local taxation. A negative sign would of course suggest the opposite phenomenon. It is, however, expected that the sign would be positive, because $\theta_{1}$ would exceed $\theta_{2}$ (given $\alpha_{1}>0$ ), since the provincial population is much larger than the population of an individual municipality. The coefficient on $\mathbf{G}_{0}$ should always be negative, because the tax burden of the voter is increased when he has to share the cost of financing grants to other localities. If $\theta_{1}$ exceeds $\theta_{3}$, the coefficient on $R_{0}$ would be positive, and this would imply that the local government would find it cheaper to finance local services by user/miscellaneous fees rather than by local taxation. The expected signs on the individual characteristics variables are difficult to predict $a$ priori. They are largely empirical issues.

The choice of grants or local taxation as an appropriate means of financing local services would of course depend upon the validity of the exogeneity specification of grants. If these grants are found to be non-exogenous in local budget decisions, the estimate of the coefficient on $\mathrm{G}$ would be biased due to a 
simultaneity between grants and local spending. While earlier studies (e.g., Gramlich 1977) have generally assumed grants as exogenous, the more recent studies (e.g., Islam and Choudhry 1990, Slack 1980) considered them as endogenous. The institutional arrangements between the province and the recipient municipality make conditional grants a stable function of local expenditures, whereby the province pays a specified percentage of total local expenditures. Thus $G_{c}$ is clearly endogenous. Unconditional grants can also be considered as endogenous because they affect local expenditures and vice versa. Moreover, they should be considered as endogenous because of the relationship between grant formula and local-provincial bargaining. Several municipal factors might influence the outcome of local provincial bargaining and thus affect the formula. For example, a municipality with a large share of provincial population has more representation in the province's legislature. These elected representatives have more leverage in obtaining increased grants for the municipality than do local officials.

The central issue is whether the effects of grants can be determined from the expenditure eq.(6) in which $G$ is exogenous or whether the endogeneity of these grants should be explicitly introduced. Exogeneity is no longer considered as merely an a priori assumption, but the validity of this assumption can in fact be tested empirically by using the test procedures developed (see Appendix) by Engle and Hendry (1993).

\section{THE DATA AND ESTIMATION PROBLEMS}

The empirical work is based on time series data for 39 upper-tier municipalities in Ontario for the period 1977-1991. The data are obtained from Municipal Financial Information, Summary of Ontario Municipal Statistics, 1977-1986, and Municipal Analysis and Retrieval System (MARS). They provide information on own-source revenues, grants (see also note 4), and expenditures by categories, and socio-demographic characteristics of the municipalities. The expenditure figures aggregate salaries, services and supplies, and transfers to capi$\mathrm{tal} / \mathrm{reserve}$ funds. Municipalities are required to consolidate the transactions of approximately 2,000 local boards (e.g., library and health boards, transit commissions, etc.). All relevant variables are expressed in real per capita terms. School taxes and educational expenses are excluded from the analysis, because education is more appropriately considered as a provincial rather than a local service and it is administered by local school boards on behalf of the province.

There are a few limitations of the data that should be emphasized. First, there are no consistent data on all of the variables prior to 1977 , because of the changes 
in concepts and classification introduced in the Canadian system of financial management statistics. Second, to express the relevant variables in real terms, one should ideally use a local price index for all goods as a common deflator but because of the unavailability of this index, the consumer price index $(1991=100)$ is used. The sample data, as reported in the publications mentioned earlier, aggregate all lower tier units along with the upper tier units into 39 categories, organized by upper tier boundaries (Metro-Toronto, Regions and Counties). For example, the annual expenditures of Metro-Toronto include expenditures of the municipality of Metropolitan Toronto and its six lower tier municipalities.

\section{ESTIMATION RESULTS}

The estimation of the model is performed in two parts. In part I, some diagnostic tests are conducted by estimating eq.(6) with ordinary least squares (OLS) on the individual time series data for each of 39 municipalities, 1977-1991. These include (1) testing for autocorrelation and normality of residual errors, (2) examining the specification of the estimating model, and (3) testing the exogeneity specification of grants. The complete model is then estimated in part II, assuming grants as exogenous or endogenous, depending upon the test results.

Diagnostic test results. To test the existence and type of autocorrelation, it is assumed that the errors are autoregressive of order $p(e . g ., p=1,2,3)$ and the Lagrangian multiplier (LM) test is employed. The procedure involves using a $\chi^{2}$ statistic (with $p$ degrees of freedom) to test $\mathrm{H}_{0}:\left(\rho_{1}=\rho_{2}=\ldots=\rho_{\mathrm{p}}\right)$. The test procedure remains unchanged even if the errors are the moving-average type or a combination of autoregressive and moving average. The estimated $\chi^{2}$ values for $\mathrm{p}=1,2$, and 3 are all statistically insignificant. This implies that there is no significant evidence of first- or higher-order autocorrelation in the errors for these municipalities (the estimation results, which can be obtained from the author, are omitted for the sake of brevity). Furthermore, the statistically insignificant values of $\chi^{2}$ (Jarque-Bera $\chi^{2}$-test of normality) do not provide any significant evidence to reject the null hypothesis that the errors are normally distributed. The small values of the Akaike's information criterion AIC (expressed in logarithm) and the statistically insignificant F-ratios (Ramsey's regression specification error test, RESET) attest to an adequate specification and a parsimonious parameterization of the estimating model.

Grants are now tested for weak and super exogeneity, using the procedure described in the appendix. Eq.(A.2) is first estimated with OLS on individual time series data (1977-1991) for each of the municipalities. The results indicate that grants received by a municipality are primarily determined by its relative size. 
The predicted values of $G$ and the residual errors are used in estimating eq. (A.1) and (A.3). The OLS estimates of these equations show that $G$ is weakly exogenous in 27 municipalities, but super exogenous in 24 of them (results can be obtained from the author).

Grants are exogenous mostly in small municipalities but endogenous in large and more prosperous municipalities. One possible explanation is that large and rich municipalities are better able to negotiate for larger grants. The user fees and miscellaneous revenues are also tested as super exogenous for all municipalities, based on a similar procedure. Given these results, eq.(6) is estimated with OLS for the 24 municipalities for which the exogeneity assumption of grants is confirmed. A simultaneous equation model, consisting of eqs.(6) and (A.2), is estimated for each of the remaining municipalities, using a two-stage least square technique (2SLS) (see tables 1A and 1B). Table 1A summarizes the results for regional municipalities only. Table $1 \mathrm{~B}$, on the other hand, presents the results for county municipalities and the GLS estimates for a pooled sample of all municipalities over the period 1977-1991.

Empirical estimates of the model from time series data. The system of equations in the model is identified. The estimated income coefficients are all positive. They are, however, significant only in 60 percent of the municipalities. The coefficient on $G$ is positive significant in 27 municipalities (10 regions and 17 counties), implying that these governments found it cheaper to finance local spending by provincial grants than by local taxation. The grant coefficient is also found to be positive (negative) but insignificant in eleven (one) municipalities. Because these coefficients are insignificant, no meaningful conclusions can be deduced from them.

The positive signs on the grant coefficients indicate that own grants contributed to the increase in local spending on public services by way of reducing their tax prices and/or increasing the average income of local residents. The expenditure response to grants seems to be less than proportional, as indicated by the elasticity coefficients; and, furthermore, it varies quite widely from one municipality to another. To explain these variations, the estimated coefficient on $G$ is regressed on various municipal factors:

$$
\begin{aligned}
& \text { Coefficient on } \mathrm{G}=4.5649^{*}+0.0450^{*} \mathrm{Y}_{\mathrm{a}}+0.0844(\mathrm{~N} / \mathrm{P})_{\mathrm{a}} \\
& \text { (t-ratios) } \\
& \text { (2.58) (-2.03) } \\
& \begin{array}{l}
-12.6260^{*}\left(A_{g}\right)_{a} ; \quad \text { S.E.E. }=0.0212, R^{2}=0.9145, \quad \text {, (7) } \\
(-1.99)
\end{array}
\end{aligned}
$$


where * indicates that the coefficient is significant at the 5 percent level and the subscript (a) indicates averaging of series over the sample period. Eq.(7) shows that the expenditure-response to grants varies across municipalities due to the variations in the size of the municipality, the age composition and average income of its population.

The coefficient on $R_{0}$ (user fees) is found to be statistically significant in one-third of the municipalities (ten with a positive sign and three with a negative sign). The estimated coefficient is also positive but insignificant in 18 other municipalities. Thus it seems that almost 70 percent of the municipalities would find it a better choice to finance local services by user fees than by local taxation. However, this conclusion is tentative, as the coefficients are not all significant.

It may be of some interest to find whether or not the institution of user fees provides a viable alternative to other means of financing local public services. To investigate this issue, all grant variables are excluded from eq.(6) and it is then estimated on the individual time series data for each municipality. The exclusion of the grant variables has an added advantage of increasing the degrees of freedom. The results (not reported for the sake of brevity) show that the coefficient on $R_{0}$ is now positive-significant in 23 municipalities and negative-significant in two municipalities (e.g., Renfrew, Lenox-Addington). This implies that in the absence of a grant system a majority of the municipalities would find it attractive to finance local services by charging user fees and thus discourage all wasteful unnecessary consumption of these services. To compare the relative cost effectiveness of grants and user fees in financing local services, the difference between $\theta_{2}{ }_{2}$ and $\theta_{3}^{e}$ is computed for each municipality from the parameter estimates (see tables 1A and 1B). The superscript (e) indicates henceforth an estimate of an unknown parameter. The results indicate that 23 municipalities would prefer grants, and 16 , user fees, in financing their public expenditures.

The coefficient on grants to all other municipalities $\left(G_{0}\right)$ is negative-significant in 15 municipalities. This provides some empirical evidence of "tax importing" due to financing grants to other communities. The tax base variable (A) appears with a positive-significant coefficient in seven municipalities and a negative-significant coefficient in five municipalities. The household size $\mathrm{H}$ is found to be positive (negative) significant in nine (two) municipalities. The proportion of young people $\left(\mathrm{A}_{\mathrm{g}}\right)$ is more often negative-significant (8 municipalities) than it is positive-significant (4 municipalities). Thus a larger tax base and an increased household size seem to have some stimulating effect on local spending. The results also include two information criteria, $\mathbf{R}^{2}$ and S.E.E. These are included as measures of precision of estimates. The significantly large values of the adjusted coefficient of determination and the small values of the standard errors of estimates attest to the precision of the parameter estimates. The parameter $\beta_{1}$ is es- 
timated for all municipalities (see tables $1 \mathrm{~A}$ and $1 \mathrm{~B}$ ). $\boldsymbol{\beta}_{2}^{\mathrm{e}}$ can be obtained by subtraction from one. The estimated values of $\beta_{1}$ vary widely across the municipalities. The results suggest that a representative voter's spending for local services constitutes roughly 6 percent of his overall spending.

Estimates of the model from pooled data. It may, however, be argued that the estimated parameters based on a small sample of 14 observations may not be efficient. The model is therefore estimated on a pooled time series and cross-section data base, with 546 observations. To overcome the problem of autocorrelation and heteroscedasticity in errors plus the endogeneity of grants a generalized least squares (GLS) procedure is used to estimate the model.

The GLS estimates of expenditure responses to grants (and other factors), based on pooled data, are reported in table 1B (last column). The coefficients on income, grants, user fees/other revenues and age composition of people are now all positive-significant. The positive-significant coefficient on $\mathbf{R}_{0}$ reinforces our earlier presumption that charging user fees could probably be a viable alternative to the costly provincial grant system. Note that the coefficient on $G_{0}$ are all negative, indicating a cost to each and every municipality arising from the financing of the overall grants. The changes in the age composition of the people, income and own grants seem to have positive influence on local expenditure expansion. In contrast to the time series results, the pooled results do not provide any empirical evidence of the stimulating effects of the change in the household size and that of the assessment practice.

Policy implication of the results. The results show that a representative voter's shares of local taxes $\left(\theta_{1}\right)$ is higher than his shares of both the cost of grant financing $\left(\theta_{2}\right)$ and user fees/miscellaneous charges $\left(\theta_{3}\right), \theta_{2}^{e}$ exceeds $\theta_{3}^{e}$ in the case of 23 municipalities. These findings have important policy implications.

Property taxes, commonly referred to as 'local taxes,' account for roughly half of local revenues, followed by provincial grants and user fees/miscellaneous non-tax revenues. The economic slowdown since late 1970s and the overall budget cuts in the province have resulted in a continual decline in transfer to the local governments. Thus the local authorities have been relying more and more on local taxation and other revenues.

They found it politically expedient to keep the local tax rate more or less unchanged from year to year but collect more tax revenues by blending the local taxes with some property-related extraordinary levies/surcharges (e.g., water tax, taxes on garbage disposal, local improvement tax, etc.). As a result, the voter's actual burden of local taxes is much higher than his share of property taxes alone. It is often argued that this additional spending benefits property owners by creating an improvement in the value of their properties through no efforts of their own (Bird and Slack 1983). 
But the decisions to undertake these additional expenditures are made by local authorities and the property owners have hardly any choice but to accept it, even if the net benefits (gross benefits-tax-cost) are negative. There are of course several alternative approaches to raise these additional funds. One approach is to require the user to pay for the services he chooses to use. The finding that $\theta_{1}>\theta_{3}$ suggests that the tax-prices of these services would be less than those under the blended local tax system. In other words, it would be more economical to partly finance local expenditures through user fees rather than by a compulsory blended local taxation. The results also indicate that roughly 60 percent ( 23 out of 39 ) of the municipalities would prefer to finance their expenditures through user fees rather than grants.

Many of the local services, which are now financed by local taxes, may be included in a category, 'pay as you use,' e.g., water consumption, refuse/garbage disposal, (frontal) snow removal, recreation facilities, etc. Given proper regulation, pricing of these services on a user basis would probably take the load out of local taxes and at the same time prevent all wasteful unnecessary consumption of these services. The finding of $\theta_{1}^{e}>\theta_{2}^{e}$ suggests that grant financing of local services would remain a preferred alternative to tax financing of these services.

\section{SUMMARY AND CONCLUSIONS}

This paper investigates whether local taxation or provincial grants (and user fees) would be more cost-effective in financing local public services. A local expenditure model is derived and tested on individual time series as well as pooled time series and cross-section data for 39 upper-tier municipalities in Ontario, Canada, 1977-1991.

The estimation of the model is preceded by testing the exogeneity specification of grants. Test results indicate that grants are both 'weak' and 'super' exogenous in 24 municipalities. These results are then taken into account in the estimation of the model, which is performed by using a two-stage least squares technique. To estimate the model on pooled data, a generalized least square method is used.

The results indicate that almost 70 percent of the municipal governments would find it cheaper to finance local spending by provincial grants than by local taxation. If, however, the grant system is abolished, a majority (23 out of 39) of these governments would prefer to use some sort of user fees in financing local services. Between grants and user charges, a majority of the local governments would prefer user fees to grants in financing their expenditures. Note that grants engender an additional tax burden for local residents because of the financing of 
grants to other communities. The GLS estimation results largely conform to the time series estimates.

The novelty of this study lies in the prior testing of the exogeneity specification of grants and incorporating the test results in the estimation of the model. A failure to do this may lead to biased and inconsistent parameter estimates. The model used in this study incorporates a number of important and realistic parametric constraints.

The results have important policy implications. They indicate that it would be cost effective if a part of the local services, which are now financed by local taxation (e.g., water consumption, refuse/garbage disposal, recreation facilities, etc.), is financed by user fees. Given proper regulation, pricing of these services on a user basis would probably take the load out of local tax rate and prevent all wasteful unnecessary consumption. It would also be worthwhile to investigate whether privatization of some of the local public services would be more cost effective than the existing system of local finance.

\section{ENDNOTES}

1. The words 'local' and 'municipal' are henceforth used synonymously.

2. The expected vote maximization (EVM) approach is preferred to the more commonly used median voter and agenda-setter models because of the following reasons. The assumptions of the median voter model (e.g., the preference distribution is single-peaked, corresponding to the median voter, the level of resources raised by taxation and grants are exogenously fixed, local budget allocation are less affected by bureaucratic politics and special interest group maneuvering, and so on) are inconsistent with the stylized facts reflected in Ontario municipal data. The overall budget structure is inherently multi-dimensional in character, involving various interest groups. The budget allocation is affected by bureaucratic politics, lobbying efforts of special groups and the institutional arrangement between the province and municipalities. As a result, the actual allocation of funds does not conform to the one preferred by the median voter. The EVM model can, on the other hand, easily incorporate these phenomena. As Fisher (1982) notes, the agenda-setter model yields an ambiguous prediction of the flypaper effect.

3. Miscellaneous other non-tax revenues come from sales of goods and services, fines, licenses/permits, interest/penalties on taxes, rentals, remittances from own enterprises, concessions and franchises, grant-in-lieu-of-taxes, and so on.

4. Ontario municipal statistics are reported on a fund basis: the revenue fund, capital fund, and reserve fund. The first one reports ordinary expenditures 
(salaries, services, and supplies, etc.) and items such as debt charges, transfers to capital/reserve fund, etc. The second one accounts for spending to create or extend the useful life of plant and equipment. The third one accounts for money put aside for application on designated projects at a later date to cover future liabilities and to provide for working funds or contingencies. The expenditures under the first two funds are included in the current account.

5. External funds come mainly from the provincial government, with a few federal government transfers amounting to less than 1 percent of total revenues. Most provincial grants to municipalities are closed-ended matching conditional transfers given for specific purposes with explicit or implicit limits as to the amount the municipality can receive. Each grant program has some unique feature, whether it be the formula, the conditions (e.g., commitment to finance a specified percentage of project costs from own-source revenues, requirement for provincial approval of all eligible costs and spending on each project, etc.), or other rules and procedures to distinguish from other grants. More than 90 percent of the grants have some sort of conditions attached to them. These are payable as lump-sum payments (e.g., per capita grants for libraries and clinics). The unconditional transfers include general purpose grants (e.g., police per capita grants, general or special support grants, and equalization grants). The main purposes of these grants are to improve the fiscal capacity of municipalities with belowaverage tax bases, and to reduce the cost of providing municipal services.

6. Equalized taxable assessment represents the market value of all residential properties in a municipality which are assessed for property tax purposes by the provincial authority.

7. The tax price of a subsidized service is equal to $\left(\theta_{1} T+\theta_{2} G_{T}\right) / \theta_{0} E$. To understand the tax effect of a grant, let the municipality reduce its tax revenues by $\$ \mathrm{G}$, which is compensated by the province with a grant of the same amount. As a result, the tax price of the good will decline by $\left(\theta_{1}-\theta_{2}\right) \mathrm{G} / \theta_{0} \mathrm{E}$, assuming that $\theta_{1}-\theta_{2}$ is positive. This will lead to a rise in the demand for these services, with an increase in their expenditures.

8. Few major policy changes took place in 1984. Per capita grant rates were converted to per household grant rates. This benefitted municipalities with a large number of cottages, as seasonal residents are not counted in the population census. The revenue guarantee in the resource equalization grant (REG) component was replaced by a total revenue guarantee. This guaranteed that no municipality would lose funds due to policy changes, and, further, all municipalities were guaranteed a maximum increase of 2.5 percent over their 1983 total grant levels. Additionally, a ceiling cap of $\$ 7$ per capita was added to the REG and a three-year averaging of the equalization factor was incorporated. 
9. It may be easily checked that both eqs.(A.1) and (A.2) meet the order condition of identification. Both the equations are, in fact, over-identified.

\section{REFERENCES}

Bird, R.M., and N.E. Slack. Urban Public Finance in Canada. Butterworths, Toronto, 1983.

Courant, P. N., E. M. Gramlich, and D. L. Rubinfeld. "The Stimulative Effects of Intergovernmental Grants: Or Why Money Sticks Where It Hits. In Fiscal Federalism and Grants-in-Aid, ed. by P. Mieszkowski and W. H. Oakland, 5-21. Washington, D.C.: The Urban Institute, 1979.

Engle, R. F., D. F. Hendry, and I. F. Richard. Exogeneity. Econometrica 51, (1983): 277-304.

Engle, R. F., and D. F. Hendry. "Testing Super Exogeneity and Invariance in Regression Models." Journal of Econometrics 56, (1993): 119-139.

Fisher, R. C. "Income and Grant Effects on Local Expenditures: The Flypaper Effect and Other Difficulties." Journal of Urban Economics 12, (1982): 324 345.

Fischer, A. M. "Policy Regime Changes and Monetary Expectations." Journal of Monetary Economics 24, (1989): 423-436.

Gramlich, Edward M. "Intergovernmental Grants: Review of the Empirical Literature." In The Political Economy of Fiscal Federalism, edited by W. E.

Oates. Lexington, Mass.: Lexington Books, 1977.

Hettich, W., and S. L. Winer. "A Positive Model of Tax Structure." Journal of Public Economics 24, (1984): 67-87.

Islam, M. N., and S. A. Choudhry. "Exogeneity of Grants to Local Governments." Canadian Journal of Economics 23(3), (August 1990). 676-692.

Islam, M. N. "On Weak and Super Exogeneity of Grants." Mimeo. Concordia University, Montreal, Canada, 1994.

McGuire, M. C. "A Method for Estimating the Effect of a Subsidy on the Receiver's Resource Constraint: With an Application to U.S. Local Governments, 1864-71." Journal of Public Economics 10, (1978): 25-44.

Meyers, H. G. "Displacement Effects of Federal Highway Grants." National Tax Journal 40(2), 221-235.

Oates, W. E. "Lump-sum Intergovernmental Grants Have Price Effects." In Fiscal Federalism and Grants-in-Aid, ed. by P. Mieszkowski and W. H. Oakland. Washington, D.C., The Urban Institute, 1979.

Romer, T., and H. Rosenthal. "An Institutional Theory of the Effect of Intergovernmental Grants. National Tax Journal, (December 1982): 451-458. 
Slack, E. "Local Fiscal Response to Intergovernmental Transfers." Review of Economics and Statistics 63 (1980): 364-370.

Wildasin, D. E. "The Demand for Public Goods in the Presence of Tax Exporting," National Tax Journal (1987): 591-600

Winer, S. L. "Some Evidence on the Effects of the Separation of Spending and Taxing Decisions." Journal of Political Economy 91 (1983): 162-140.

Zampelli, E. M. "Resource Fungibility, the Flypaper Effect and the Expenditure Impact of Grants-in-Aid." Review of Economics and Statistics 67 (1986): 3340. 


\section{APPENDIX}

Engle et al. (1983) proposed three different notions of exogeneity ('weak,' 'strong,' and 'super'), along with their respective test procedures. Weak exogeneity is required for efficient estimation of a conditional model $E\left(E_{t} / G_{t}, L_{t}\right)$, where $I_{t}$ is an information set that includes other determinants of $E_{t}$ at time $t$. Strong exogeneity is necessary for conditional forecasting and super exogeneity validates policy analysis subject to regime changes. ${ }^{8}$ Weak exogeneity is a necessary condition for both strong and super exogeneity.

Assuming $E_{t}$ and $G_{t}$ as normally distributed with means $\mu_{E t}$ and $\mu_{G t}$ and constant variances, the weak exogeneity of $G_{t}$ can be examined by using the following test regression equation (see Engle and Hendry 1993, Islam 1994):

$$
E_{t}=a_{0 t} \hat{G}^{e}{ }_{t}+a_{1} v^{v^{e}}{ }_{t}+\sum \mathrm{a}_{(1+\mathrm{i}) t} S_{i t}+u_{t} ; u_{t} \sim \operatorname{IN}\left(O, \sigma_{u}^{2}\right), \quad i=1,2, \ldots k,
$$

under the null hypothesis $\mathrm{H}_{0}\left(\mathrm{a}_{1 \mathrm{t}}=0\right)$. The variables $\mathrm{S}_{\mathrm{it}}$ represent the set of all other exogenous determinants of local expenditures (see eq.6). The variables $\hat{G}_{\mathrm{t}}{ }_{\mathrm{t}}$ and $v_{t}^{e}$ are the estimates of $G_{t}$ and $v_{t}$ from the grant function:

$$
G_{t}=b_{0}+\Sigma b_{i} Z_{i t}+v_{t} ; v_{t}-\mathbb{N}\left(0, \sigma_{v}^{2}\right) \text {. }
$$

The variable $Z_{i t}$ includes the determinants of $G_{t}$ (e.g., the lagged per capita local expenditures, per capita income of local residents, the change in per capita municipal taxes, the relative size of the municipality, the percentage of young people, 0-19 years old in municipal population, and the household size). Weak exogeneity of $G_{t}$ requires that the coefficient on $v_{t}^{e}$ is not significantly different from zero.

Strong exogeneity requires that $G_{t}$ is first of all weakly exogenous for the parameter of interest $a_{0}$, and further, it is not Granger-caused by $E_{t}$. Super exogeneity requires that $G_{t}$ is weakly exogenous for $a_{0 t}$ and its estimate is invariant to regime shifts. Assuming that the variance of grants remains constant over the regime shifts, the null hypothesis of super exogeneity can be tested (as in Fisher 1989) by using the test regression ${ }^{9}$ :

$\mathrm{E}_{\mathrm{t}}=\mathrm{b}_{0}+\mathrm{b}_{1} \mathrm{G}_{\mathrm{t}}+\mathrm{b}_{2} \mathrm{v}^{\mathrm{e}}{ }_{\mathrm{t}}+\mathrm{b}_{3}\left(\mathrm{v}_{\mathrm{t}}^{\mathrm{e}}\right)^{2}+\Sigma \mathrm{b}_{(3+\mathrm{i}) \mathrm{t}} \mathrm{S}_{\mathrm{it}}+\mathrm{u}_{\mathrm{t}} ; \quad \mathrm{u}_{\mathrm{t}} \sim \mathrm{IN}\left(0, \sigma_{\mathrm{Et}}{ }^{2}\right)$,

where the null hypothesis of invariance is $\mathrm{H}_{0}\left(\mathrm{~b}_{2}=\mathrm{b}_{3}=0\right)$. An unique feature of super exogeneity testing is that the variables $\left(\mathrm{Z}_{\mathrm{it}}\right)$ in the grant equation (A.2) as well as eq.(A.3) should include a variable allowing for and defining regime shifts. 
Super exogeneity of grants requires that the mean and higher moments (e.g., variance) of grants do not appear in eq.(A.3). The exclusion of these moments requires in turn that the coefficients $b_{2}$ and $b_{3}$ are both statistically insignificant. Similar procedure may also be used to test the exogeneity of $R_{0}$. 


ํㅗㅇ

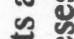

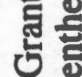

놈

淧.5

응

ชั

电运

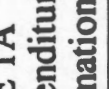

这.

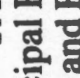

(5)

s:

政

(a)

象

흘

政

줄

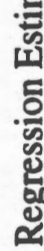

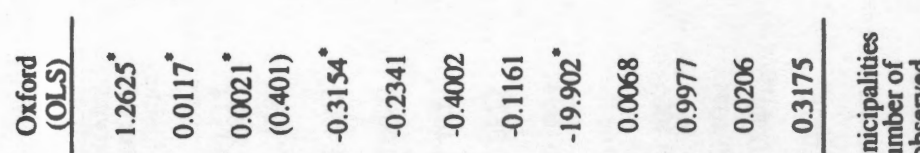

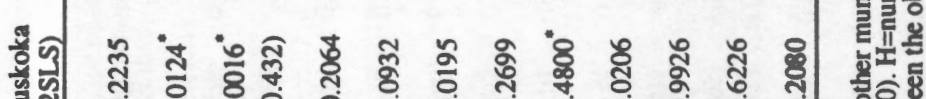

亦部

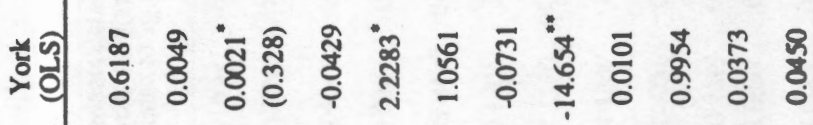

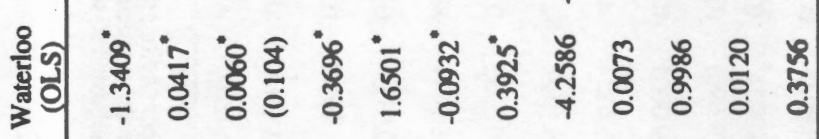

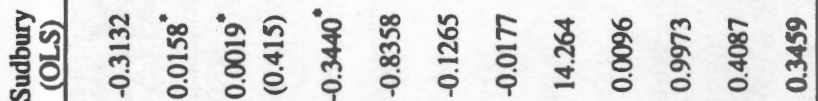

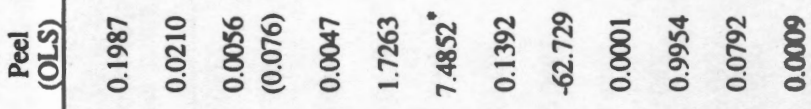

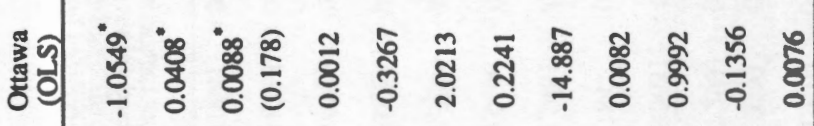

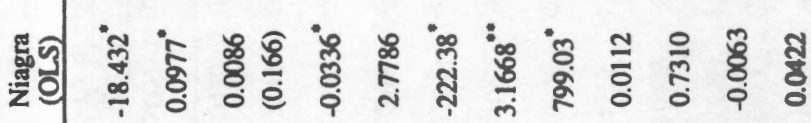

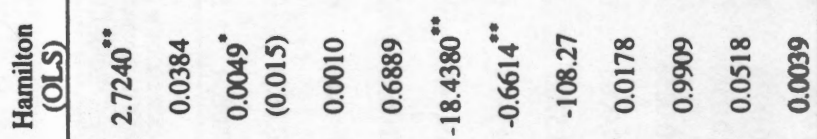

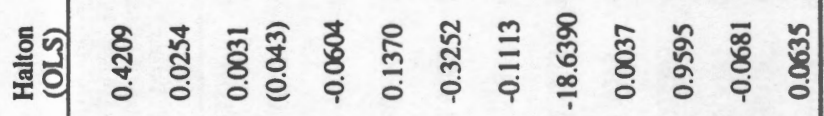

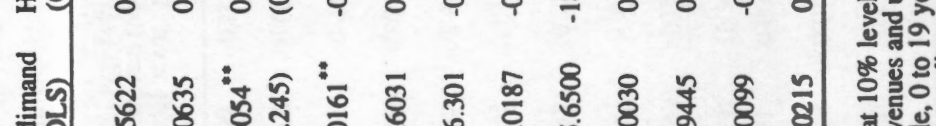

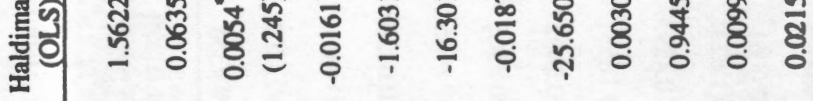

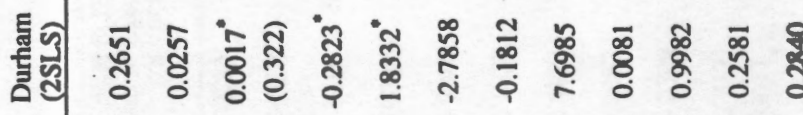

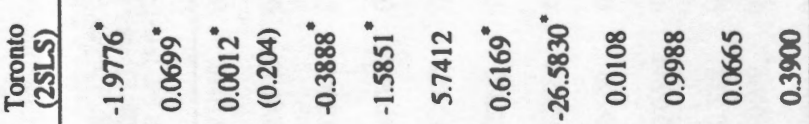

恖 


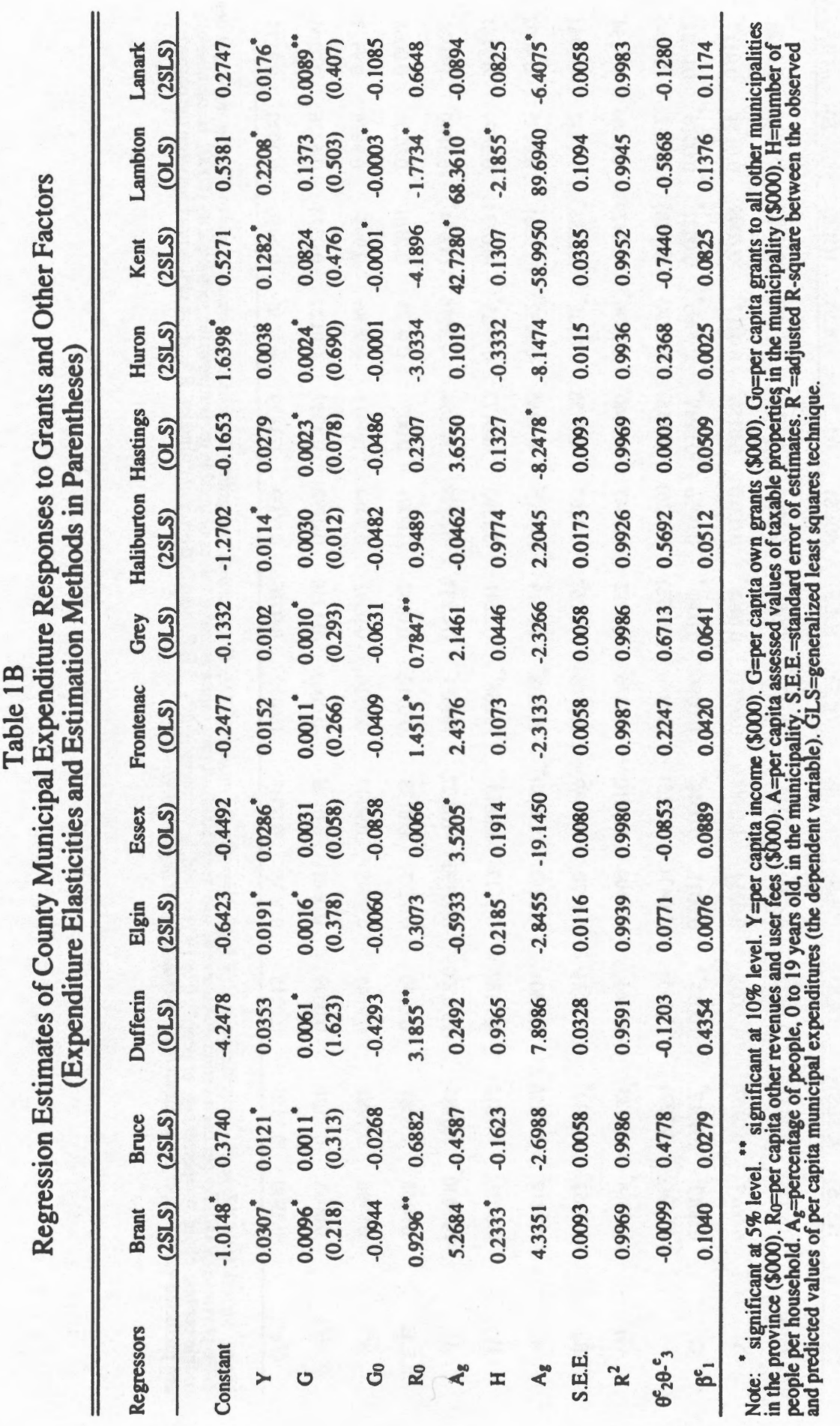


总

흐 ᄚ

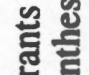

ธั่

온 둔

\&. 5

등 용

는

ठृष्ठ

는

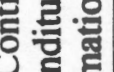

\&.

ำ 조

닉 응

들

空:

름푬

ชํํㄹ

政

은

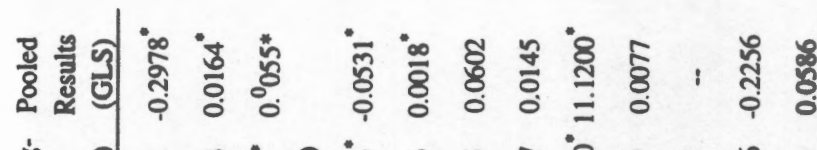

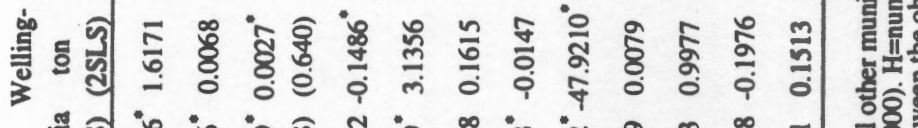

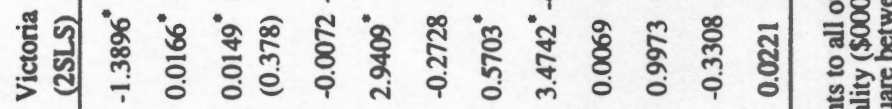

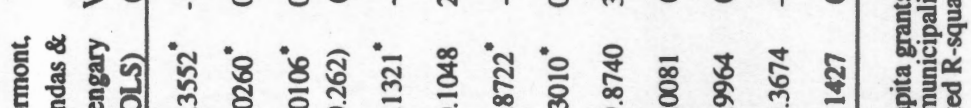
कू

岁勻

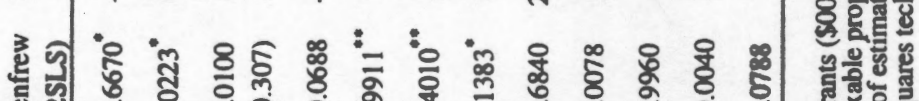

选

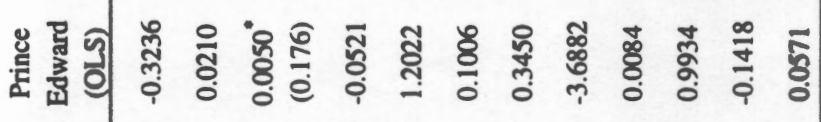

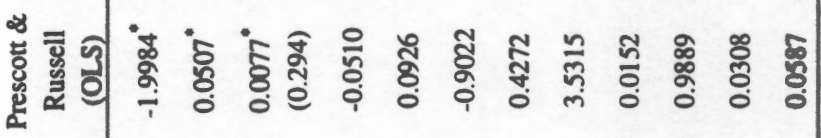

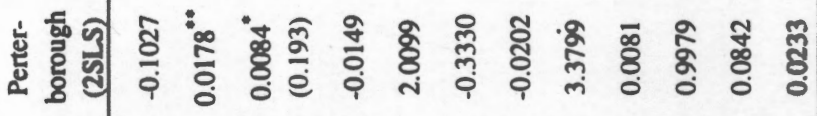

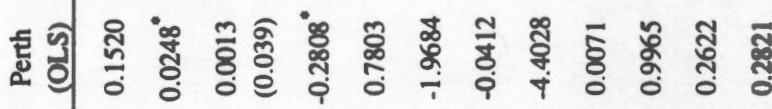

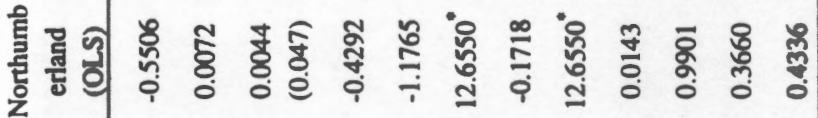

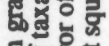

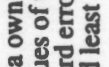

:

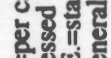

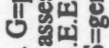

8े. ज्ञ.

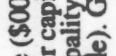

일율

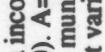

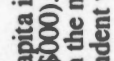

당. 5

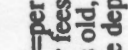

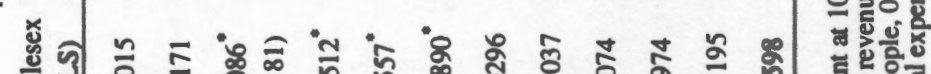

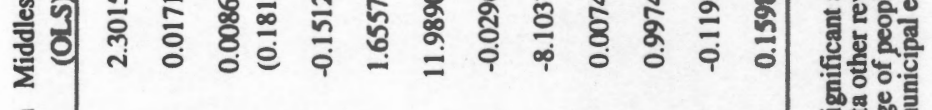

ఖ

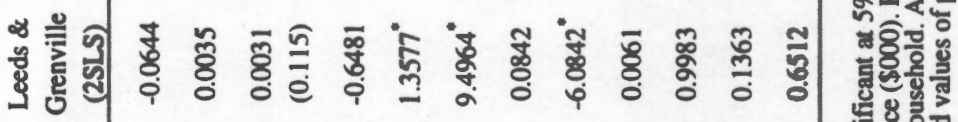
量 